\title{
Two Sexually Dimorphic Cell Groups in the Human Brain
}

\author{
Laura S. Allen, Melissa Hines, James E. Shryne, and Roger A. Gorski \\ Department of Anatomy and Laboratory of Neuroendocrinology of the Brain Research Institute, Center for Health \\ Sciences, University of California at Los Angeles, Los Angeles, CA 90024
}

\begin{abstract}
A quantitative analysis of the volume of 4 cell groups in the preoptic-anterior hypothalamic area (PO-AHA) and of the supraoptic nucleus (SON) of the human brain was performed in 22 age-matched male and female individuals. We suggest the term Interstitial Nuclei of the Anterior Hypothalamus (INAH 1-4) to identify these 4 previously undescribed cell groups in the PO-AHA. While 2 INAH and the SON were not sexually dimorphic, gender-related differences were found in the other 2 cell groups. One nucleus (INAH-3) was 2.8 times larger in the male brain than in the female brain irrespective of age. The other cell group (INAH-2) was twice as large in the male brain, but also appeared to be related in women to circulating steroid hormone levels. Since the PO-AHA influences gonadotropin secretion, maternal behavior, and sexual behavior in several mammalian species, these results suggest that functional sex differences in the hypothalamus may be related to sex differences in neural structure.
\end{abstract}

Male and female mammals exhibit differences in reproductive physiology and behavior patterns that are primarily controlled by the effects of gonadal hormones upon the brain (Goy and McEwen, 1980; Gorski, 1984). Several types of neuroanatomical sex differences have been identified in both mammalian and avian species that could underlie these functional differences. There are subtle sex differences in the size of nerve cell nuclei (Pfaff, 1966; Dörner and Staudt, 1968). At the ultrastructural level, several sexual dimorphisms have been identified in dendritic branching patterns of neurons of the preoptic area (POA) in the rat (Meyers and Gordon, 1982), hamster (Greenough et al., 1977), and the macaque monkey (Ayoub et al., 1983); and in the synaptic organization of the POA (Raisman and Field, 1971), arcuate nucleus (Matsumoto and Arai, 1981), and medial amygdala (Nishizuka and Arai, 1981) of the rat. In addition to these subtle microscopic differences, there exist dramatic dimorphisms in cell groups involved in vocal communication in canaries and finches (Nottebohm and Arnold, 1976); in the bed nucleus of the stria terminalis (BNST) in guinea pigs (Hines et al., 1985) and in rats (del Abril et al., 1987); and in the POA

Received Apr. 5, 1988; revised July 8, 1988; accepted July 18, 1988.

This research was supported by NIH Grants AG-00122, HD 01182 , NS 20687, and HD 19644. We thank Dr. Anthony Verity and Dr. Wilmier Talbert for supplying the brain tissue, Carla Johnson for histological preparation of these samples, Myles Morimoto for computer quantification of nuclear areas, Dr. Peter Christenson of UCLA's Statistical/Biomedical Consulting Clinic for statistical advice, and Dr. Arnold Scheibel for assisting in the naming of the Interstitial Nuclei of the Anterior Hypothalamus.

Correspondence should be addressed to Laura S. Allen, Department of Anatomy, UCLA School of Medicine, University of California, Los Angeles, Los Angeles, CA 90024.

Copyright $(1989$ Society for Neuroscience $0270-6474 / 89 / 020497-10 \$ 02.00 / 0$ of rats (Gorski et al., 1978, 1980), gerbils (Yahr and Commins, 1982), guinea pigs (Hines et al., 1985), ferrets (Tobet et al., 1986), and quail (Panzica et al., 1987).

Despitc many reports of sexually dimorphic structures in mammalian and avian species, relatively little is known about neuroanatomical sex differences in the human brain. There are gender-related allometric variations in brain weight and evidence for sexual dimorphism in morphological brain asymmetry (Wada et al., 1975). In addition, the massa intermedia (MI) is more often present (Rabl, 1958), and both the MI (Allen and Gorski, 1987) and the anterior commissure (Allen and Gorski, 1986) are larger at the midsagittal plane in women than in men. Similarly, sex differences in the corpus callosum have been reported (de LaCoste-Utamsing and Holloway, 1982), although not all subsequent studies have replicated this finding. However, there remains a dearth of documented volumetrically sexually dimorphic cell groups in the human brain (Swaab and Fliers, 1985).

Because the POA shows the greatest number of reported gendcr-rclatcd dimorphisms in other mammalian species, it is a likely site for similar differences in humans. Furthermore, the POA has been implicated in several reproductive functions in the rat and subhuman primate such as gonadotropin release (Gorski, 1968; Plant et al., 1979; Pohl and Knobil, 1982; Wiegand and Terasawa, 1982), maternal behavior (Jacobson et al., 1980), and sexual behavior (Robinson and Mishkin, 1966; Gorski, 1974; Arendash and Gorski, 1983; Oomura et al., 1983). Since there are no clear boundaries in the human brain between the POA and the anterior hypothalamus, and, in fact, some anatomists consider the POA to be the anterior region of the anterior hypothalamus, we selected the preoptic-anterior hypothalamic area (PO-AHA) for quantitative analysis of possible sexually dimorphic nuclei in the human brain.

\section{Materials and Methods}

The brains of 22 human subjects, which were determined to be normal upon autopsy and were from individuals who had no known neurological disorder, were chosen from our brain bank of about 100 hypothala$\mathrm{mi}$ to represent a chronological range of age-matched male and female individuals. All of these brains were collected from 1 of 2 Southern California hospitals, removed from their skulls within $8 \mathrm{hr}$ post-mortem, and placed directly in acetate-buffered $10 \%$ formalin (ABF) for $2-4$ weeks prior to coronal sectioning performed during routine autopsy. Hypothalami were dissected from these coronal slabs, and these samples, approximately $3 \mathrm{~cm}^{3}$, were saved for 3 months to 2 years prior to histological preparation. No changes due to duration of fixation were observed when comparing the volume of nuclei from brains that had been fixed for less or more than a year (ANOVA; $p>0.05$ ). Subsequently, all samples were processed for histology in age-matched pairs as described below.

Immersion in gelatin. Blocks were rinsed overnight in cool water to remove $\mathrm{ABF}$, immersed in $5 \%$ gelatin at $37^{\circ} \mathrm{C}$ for $24 \mathrm{hr}$, immersed in 
Table 1. Individual data on the interstititial nuclei of the anterior hypothalamus (INAH), SON, cause of death, and race

\begin{tabular}{|c|c|c|c|c|c|c|c|c|c|}
\hline Pair & $\begin{array}{l}\text { Age } \\
(\mathrm{yr})\end{array}$ & $\begin{array}{l}\text { Brain } \\
\text { weight } \\
\text { (gm) }\end{array}$ & $\begin{array}{l}\text { INAH-1 } \\
\text { volume } \\
\left(\mathrm{mm}^{3}\right)\end{array}$ & $\begin{array}{l}\text { INAH-2 } \\
\text { volume } \\
\left(\mathrm{mm}^{3}\right)\end{array}$ & $\begin{array}{l}\text { INAH-3 } \\
\text { volume } \\
\left(\mathrm{mm}^{3}\right)\end{array}$ & $\begin{array}{l}\text { INAH-4 } \\
\text { volume } \\
\left(\mathrm{mm}^{3}\right)\end{array}$ & $\begin{array}{l}\text { SON } \\
\text { volume } \\
\left(\mathrm{mm}^{3}\right)\end{array}$ & Cause of death & Race \\
\hline \multicolumn{10}{|l|}{ Males } \\
\hline 1 & 5 & 1210 & 0.424 & 0.046 & 0.095 & 0.049 & 6.552 & Lymphoblastic leukemia & Hispanic \\
\hline 2 & 29 & 1460 & 0.404 & 0.049 & 0.078 & 0.149 & 6.570 & Lymphoblastic leukemia & White \\
\hline 3 & 29 & 1270 & 0.465 & 0.037 & 0.130 & 0.004 & 9.569 & Burkitt's lymphoma & White \\
\hline 4 & 31 & 1490 & 0.452 & 0.048 & 0.103 & 0.205 & 9.252 & Chronic myelogenous leukemia & White \\
\hline 5 & 43 & 1400 & 0.343 & 0.100 & 0.156 & 0.045 & 8.751 & Neuroadenoma & Hispanic \\
\hline 6 & 58 & 1450 & 0.321 & 0.046 & 0.132 & 0.150 & 6.199 & Squamous cell carcinoma & White \\
\hline 7 & 58 & 1195 & 0.271 & 0.046 & 0.138 & 0.082 & 5.804 & Heart disease & White \\
\hline 8 & 63 & 1250 & 0.473 & 0.030 & 0.315 & 0.077 & 7.583 & Heart disease & White \\
\hline 9 & 68 & 1240 & 0.366 & 0.026 & 0.113 & 0.070 & 6.010 & Heart disease & White \\
\hline 10 & 72 & 1420 & 0.241 & 0.029 & 0.126 & 0.038 & 7.285 & Heart disease & White \\
\hline 11 & 81 & 1380 & 0.267 & 0.030 & 0.068 & 0.073 & 4.259 & Adenocarcinoma & White \\
\hline Mean & 48.8 & 1342.3 & 0.366 & 0.044 & 0.132 & 0.086 & 7.076 & & \\
\hline SFM & 6.66 & 31.68 & 0.024 & 0.006 & 0.019 & 0.017 & 0.487 & & \\
\hline \multicolumn{10}{|c|}{ Females } \\
\hline 1 & 4 & 1120 & 0.512 & 0.005 & 0.005 & 0.003 & 5.435 & Heart disease & White \\
\hline 2 & 20 & 1350 & 0.431 & 0.041 & 0.085 & 0.127 & 6.514 & Burkitt's lymphoma & White \\
\hline 3 & 25 & 1150 & 0.421 & 0.050 & 0.008 & 0.078 & 4.937 & Aplastic anemia & White \\
\hline 4 & 32 & 1200 & 0.218 & 0.047 & 0.062 & 0.102 & 7.511 & Budd-chiari syndrome & White \\
\hline 5 & 44 & 1275 & 0.240 & 0.011 & 0.034 & 0.016 & 6.862 & Sickle cell disease & Black \\
\hline 6 & 61 & 1280 & 0.211 & 0.014 & 0.029 & 0.048 & 4.843 & Adenocarcinoma & White \\
\hline 7 & 63 & 1090 & 0.310 & 0.009 & 0.006 & 0.044 & 7.226 & Heart disease & White \\
\hline 8 & 64 & 1190 & 0.248 & 0.010 & 0.102 & 0.018 & 6.306 & Cryptogenic cirrhosis & White \\
\hline 9 & 69 & 1280 & 0.234 & 0.009 & 0.059 & 0.096 & 6.196 & Heart disease & White \\
\hline 10 & 72 & 1250 & 0.244 & 0.027 & 0.081 & 0.066 & 5.560 & Heart disease & White \\
\hline 11 & 81 & 1260 & 0.216 & 0.015 & 0.049 & 0.017 & 4.677 & Diabetes mellitus & White \\
\hline Mean & 48.6 & 1222.3 & 0.299 & 0.022 & 0.047 & 0.056 & 6.007 & & \\
\hline SEM & 7.200 & 22.758 & 0.030 & 0.005 & 0.010 & 0.012 & 0.296 & & \\
\hline
\end{tabular}

$10 \%$ gelatin for $24 \mathrm{hr}$, embedded in $10 \%$ gelatin, which was allowed to solidify at room temperature, trimmed of excess mold to expose the brain, and placed in $10 \% \mathrm{ABF}$ for $4 \mathrm{~d}$ to harden.

Sectioning. Serial $60 \mu \mathrm{m}$ coronal sections were mounted from saline onto gelatin-coated glass slides, and incubated at $37^{\circ} \mathrm{C}$ overnight.

Staining with thionin. Sections were dehydrated with alcohol, defatted with xylene, rehydrated with distilled water, stained with $1 \%$ buffered thionin, rinsed with distilled water, differentiated with $\mathrm{ABF}$ followed by alcohol, and coverslipped out of xylene.

Since we were unable to identify any cell group clearly homologous to a sexually dimorphic nucleus of another species, 4 relatively discrete cell groups within the PO-AHA that stained darkly with thionin were selected for quantitative analysis. In our search of the literature on the human hypothalamus, we were unable to determine the nomenclature for any of these 4 cell groups, We therefore elected to name them Interstitial Nuclei of the Anterior Hypothalamus (INAH) in numerical order in a lateral to medial direction. In addition, we selected the supraoptic nucleus (SON) as a control nucleus since it has not been reported to be sexually dimorphic in another species, is located in the region of the INAH, and, like the INAII, has well-defined borders, relative to the paraventricular nucleus (PVN), the borders of which are not well-defined in the thionin-stained human brain. Serial sections of the INAH and SON were projected onto paper at $\times 44$ magnification, and the boundaries were traced independently by 3 investigators who had no knowledge as to the sex of the brains. We arbitrarily chose to draw the nuclei located on the right side of the brain. The 3 tracings were superimposed on a light box using other anatomical landmarks, and an average outline common to a minimum of 2 of the individual tracings was drawn for each section of each cell group. In general, there was close agreement among the 3 investigators, and the composite out- line approximated an average of all 3 individual drawings. We use this methodology rather than calculating an arithmetic mean of the 3 drawings because it more accurately reflects actual perceptions. For instance, in the case where 2 individuals traced a particular section, and a third individual did not, our composite drawing would represent an average drawing of the 2 investigators in agreement, rather than a smaller average based on all 3 investigators, but markedly different from the actual perception of any of the 3 individuals. This method of quantification has been employed routinely in evaluating the volume of neural structures in our laboratory (Gorski et al., 1978, 1980; Hines et al., 1985). The area of each average outline was determined using a Bioquant Hipad digitizer (Bioquant IBM Program version 2.1; R \& M Biometrics) having a resolution of $0.5 \mathrm{~mm}$. The volumes of these nuclei were calculated by summing the areas of these values, multiplying by the thickness of the sections, and correcting for magnification.

\section{Results}

Our results are based on an analysis of the brains of 11 agematched pairs of males and females. The age range for male subjects was 5-81 years (mean $\pm \mathrm{SEM}=48.8 \pm 6.7$ ) and for female subjects was $4-81$ years $(48.6 \pm 7.2)$. The averagc agc difference between pairs was 2.3 years. There was an average of $29.5 \pm 1.51$ sections per individual brain for INAH-1, 5.09 \pm 0.26 for INAH-2, $9.7 \pm 1.01$ for INAH-3, $7.95 \pm 0.97$ for INAH-4, and $83.82 \pm 3.64$ for the SON. Although the brains were cut coronally during autopsy, the angle did vary slightly between subjects, and this increased the variability in the num- 


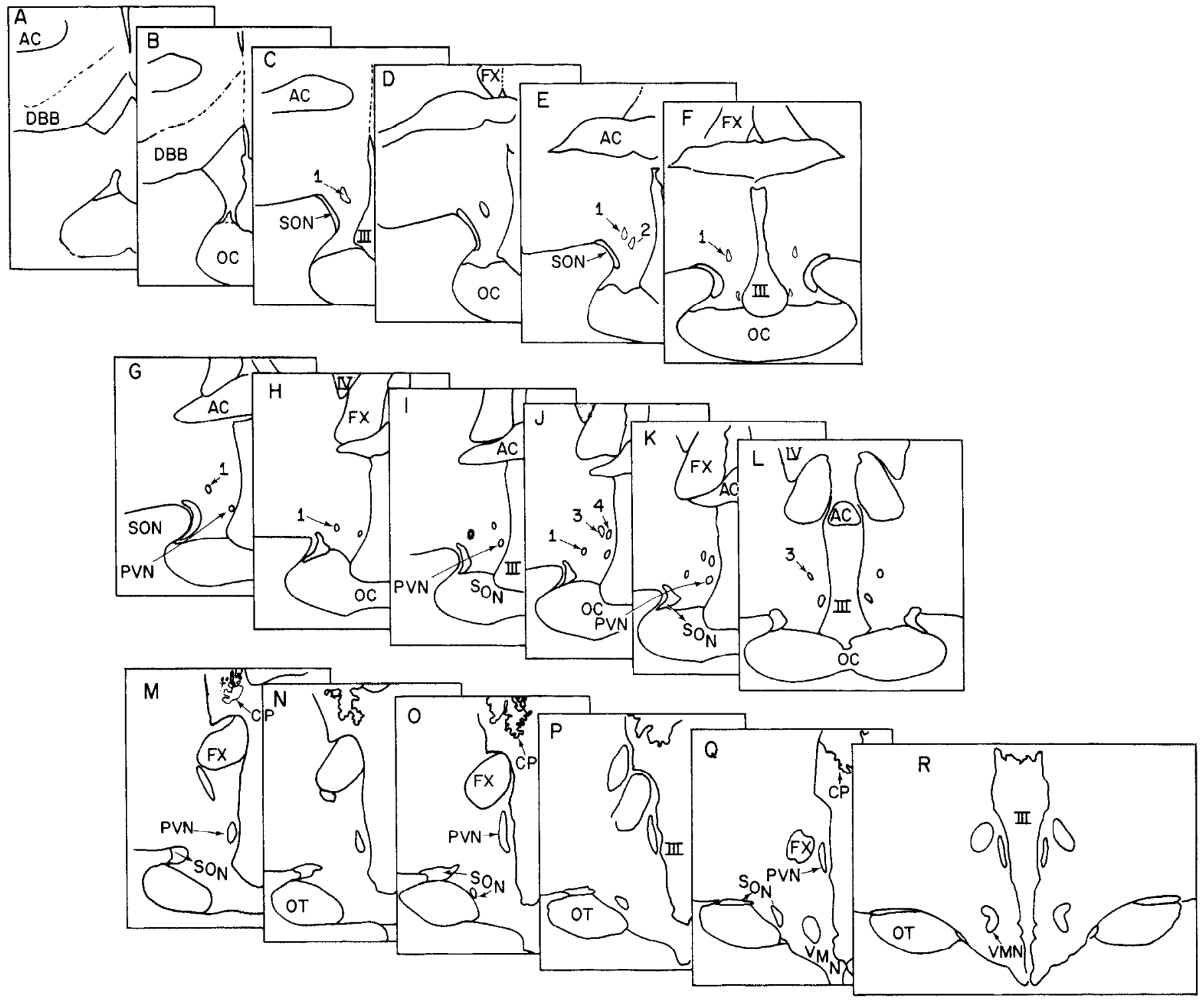

Figure 1. Schematic illustration of the nuclei analyzed in this study in the coronal plane, organized rostrally to caudally, from the diagonal band of Broca $(D B B)$ to the ventromedial nucleus $(V M N)$. This atlas was drawn from sections, all projected at the same magnification, from the 58year-old male from pair number 7 who was selected because of the similarity in the plane of section to his age-matched pair (Table 1). There are $760-\mu \mathrm{m}$-thick sections between each section from $A$ through $C$ and from $L$ through $R$. Between each section from $C$ through $L$, which contain the INAH, there are only $260-\mu$ m-thick sections. Levels $D, E, I$, and $J$ correspond to the Figures $2 A, 2 D, 2 G$, and $2 J$, respectively. Other abbreviations: anterior commissure, $A C$; optic chiasm, $O C$; INAH-1, 1 ; fornix, $F X$; third ventricle, $I I I$; INAH-2, 2 ; supraoptic nucleus, $S O N$; paraventricular nucleus, $P V N$; INAH-3, 3 ; INAH-4, 4; lateral ventricle, $L V$; choroid plexus, $C P$; and optic tract, $O T$.

ber of sections per nucleus between subjects since we could not always sacrifice hypothalamic tissue to adjust for plane of sectioning. Data were first analyzed using a paired $t$ test comparing the absolute volumes of each of the 4 cell groups for men and women (INAH-1, $p>0.05$; INAH-2, $p<0.03$; INAH-3, $p<$ 0.002 ; INAH-4, $p>0.05$; SON, $p>0.05$ ). Subsequently, we adjusted the absolute volumes for statistically significant sex differences in brain weight [average brain weight (in gm) \pm SEM for males was $1342.3 \pm 31.7$; for females, $1222.3 \pm 22.8 ; p<$ $0.001]$. First, we divided the volume of each cell group by individual brain weight and analyzed these measures with the paired $t$ test (INAH-1, $p>0.05$; INAH-2, $p<0.05$; INAH-3, $p<0.003$; INAH-4, $p>0.05$; SON, $p>0.05$ ). Second, we performed an analysis of covariance of the absolute volumes of the nuclei by sex, with brain weight as the covariate (INAH-1, $p>0.05$; INAH- $2, p<0.02$; INAH- $3, p<0.001$; INAH- $4, p$ $>0.05$; SON, $p>0.05$ ). With each of the 3 sets of statistics, INAH-2 and INAH-3 exhibited a statistically significant sexual dimorphism, while INAH-1, INAH-4, and the SON did not (Table 1). Finally, the volume of each nucleus was adjusted with Durand's approximation (Burington, 1965), and all statistical results remained the same.

INAH-2, which is twice as large in males as in females, is located between the SON and the PVN (Figs. 1 and 2) and contains relatively small cell bodies (Fig. 3). Interestingly, INAH-2 was 3.7-fold larger in women of child-bearing age $(n$ $=3 ; 20-32$ years old) than in the prepubescent $(n=1)$ and postmenopausal females $(n=7$; the 44-year-old woman in this study had a hysterectomy with ovarian removal 3 years prior to death, and is therefore not included in the group of women 

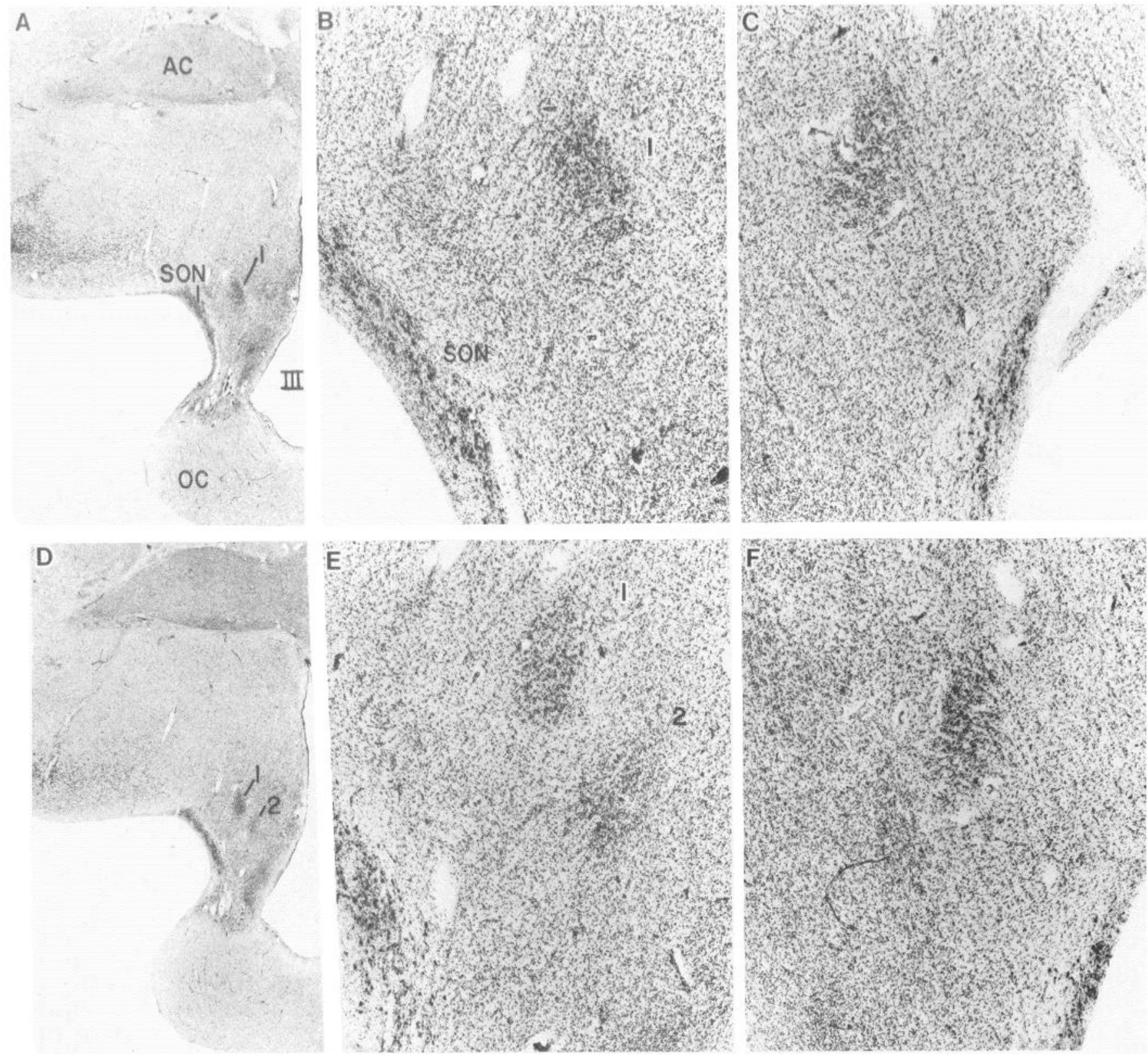

Figure 2. $A-F$, Photomicrographs of thionin-stained coronal sections of the anterior hypothalamus of the human brain. Photographs $A$ and $D$ correspond to the schematics in Figures $1 D$ and $1 E$, respectively. $B$, Higher-power view of $A$ showing greater detail of the supraoptic nucleus ( $S O N$ ) and INAH-1 (1). Similarly, $E$ is a magnification of INAH-1 $(I)$ and INAH-2 (2) from $D$. $C$ and $F$, Sections at the same magnification and in the same region as $B$ and $E$, respectively, from the 63-year-old female. Other abbreviations: anterior commissure, $A C$; optic chiasm, $O C$, and third ventricle, $I I I$. $G-L$, Photomicrographs of thionin-stained coronal sections, caudal to $A-F$, illustrating the interstitial nuclei of the anterior hypo-

of reproductive age). In fact, in the 3 women of reproductive age, INAH- 2 was of similar volume to that of the males $(0.046$ $\mathrm{mm}^{3}$ women vs. $0.044 \mathrm{~mm}^{3}$ in men). However, more data must be collected before valid statistical comparisons can be made between women of reproductive age and of nonreproductive age. None of the other 3 nuclei we quantified appeared to exhibit a similar age-related pattern of sexual dimorphism. The second sexually dimorphic nucleus that we identified, INAH-3, which was 2.8 times larger in males than in females regardless of age, is located slightly superior to the rostral pole of the PVN (Figs. 1 and 2) and has relatively large somata (Fig. 3).

The other 3 nuclei evaluated exhibited no statistically significant sexual dimorphism in volume. INAH-1, located dorso- lateral to INAH-2, between the SON and the rostral pole of the PVN (Figs. 1 and 2), is a relatively large-celled nucleus (Fig. 3). In contrast to the other $3 \mathrm{INAH}$, which are somewhat spherical in shape, INAH-1 is tubular and oriented lengthwise along the rostrocaudal axis of the brain. Linear-regression analysis of the 5 nuclei in both males and females indicated that only the volume of INAH-1 significantly decreased with advancing age [ $p$ $<0.001$; correlation coefficient $=-0.691$; slope of regression line $(M)=-0.0029 ; Y$ intercept $(B)=0.475$; therefore, if $X=$ average age \pm SEM, $Y=$ average volume \pm SEM, and $Y=B$ $+M X$, then $0.332 \pm 0.021=0.4747+(-0.0029)(48.727 \pm$ 4.9)]. INAH- 4 is also of similar size in both sexes. This nucleus, located superior to the rostral pole of the PVN and slightly 

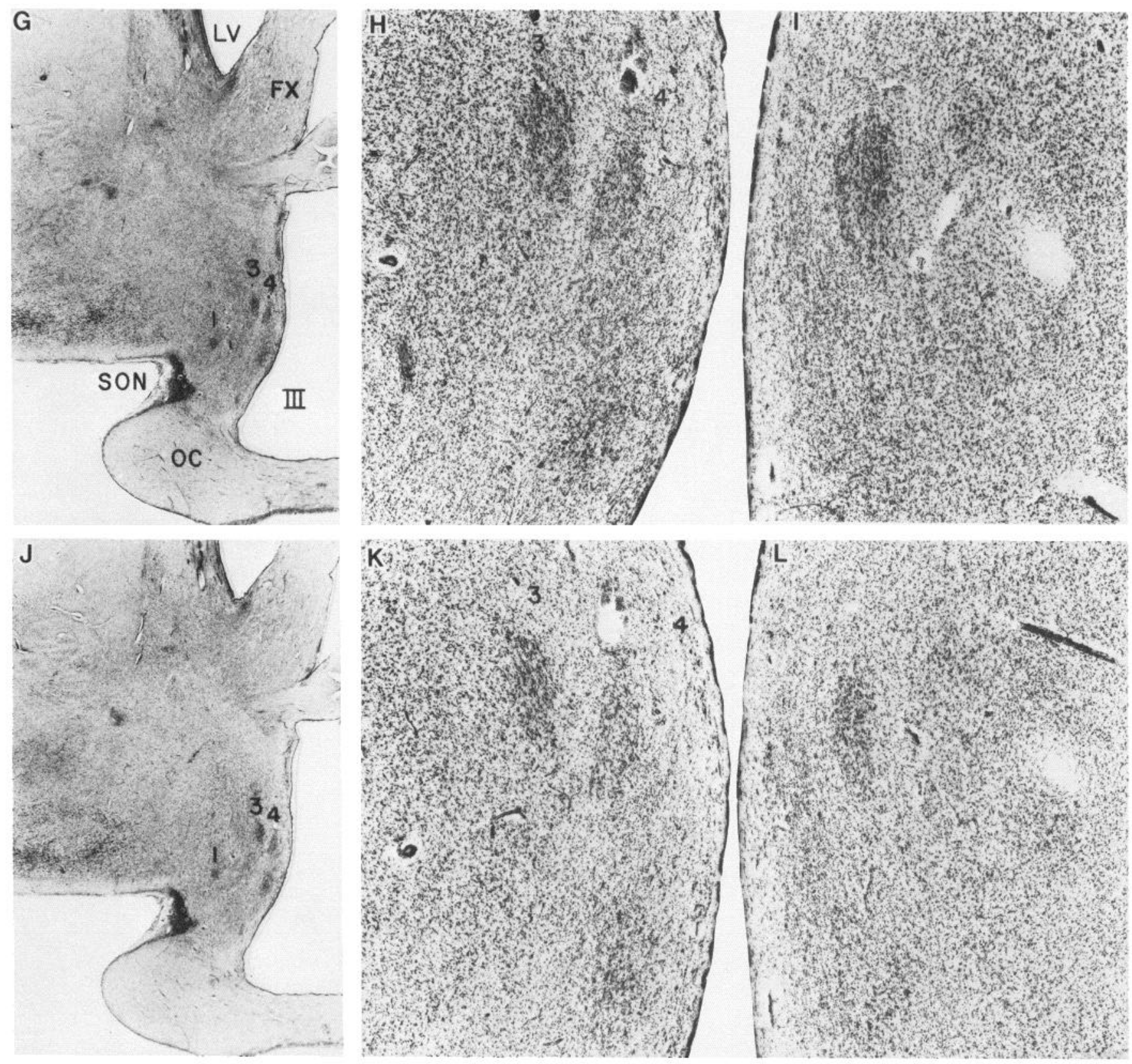

thalamus of the human brain. $G$ and $J$, Sections corresponding to the Figures $1 I$ and $1 J$, respectively. $H$, Higher-power view of $J$ showing greater detail of INAH-3 (3) and INAH-4 (4). Similarly, $K$ is a higher-power view of $J . I$ and $L$, Sections at the same magnification and in the same region as $H$ and $K$, respectively, from the 63 -year-old female. Other abbreviations: fornix, $F X$; third ventricle, $I I I$; supraoptic nucleus, $S O N$; optic chiasm, $O C$; lateral ventricle, $L V$; and INAH-1, 1 .

posteromedial to INAH-3 (Figs. 1 and 2), contains relatively small cells (Fig. 3). The similarity in nuclear volume between the male and female INAH-1, INAH-4, and the SON demonstrates that the sexual dimorphism observed in INAH-2 and INAH-3 does not reflect a general sexual dimorphism throughout the hypothalamus; rather, it is limited to certain structures.

\section{Discussion}

Homology of the INAHs to nuclei of other species

It is unclear which, if either, of the 2 nuclei we found to be sexually dimorphic in the human brain corresponds to the SDNPOA of the rat. INAH-3 exhibits similarities to the SDN-POA of the rat by virtue of its location between the optic chiasm and the anterior commissure (Figs. 1 and 2) and its relatively large cell somata (Fig. 3). However, without knowledge of connectivity or neurochemical characteristics of these nuclei, it is difficult to assign any as a homolog to a sexually dimorphic nucleus of another mammalian species. In the rat, the medial preoptic nucleus (MPN), which contains the SDN-POA, receives input from the amygdala, ventral subiculum, ventral lateral septal nuclei, bed nucleus of the stria terminalis, insular cortical areas, nucleus accumbens, substantia innominata, raphe nuclei, ventral tegmental area, periaqueductal gray, pedunculopontine nucleus, and peripeduncular nucleus (Simerly and Swanson, 1986) and projects to the ventral tegmental area, midbrain central gray (Fahrbach et al., 1986), pedunculopontine nucleus, and zona 


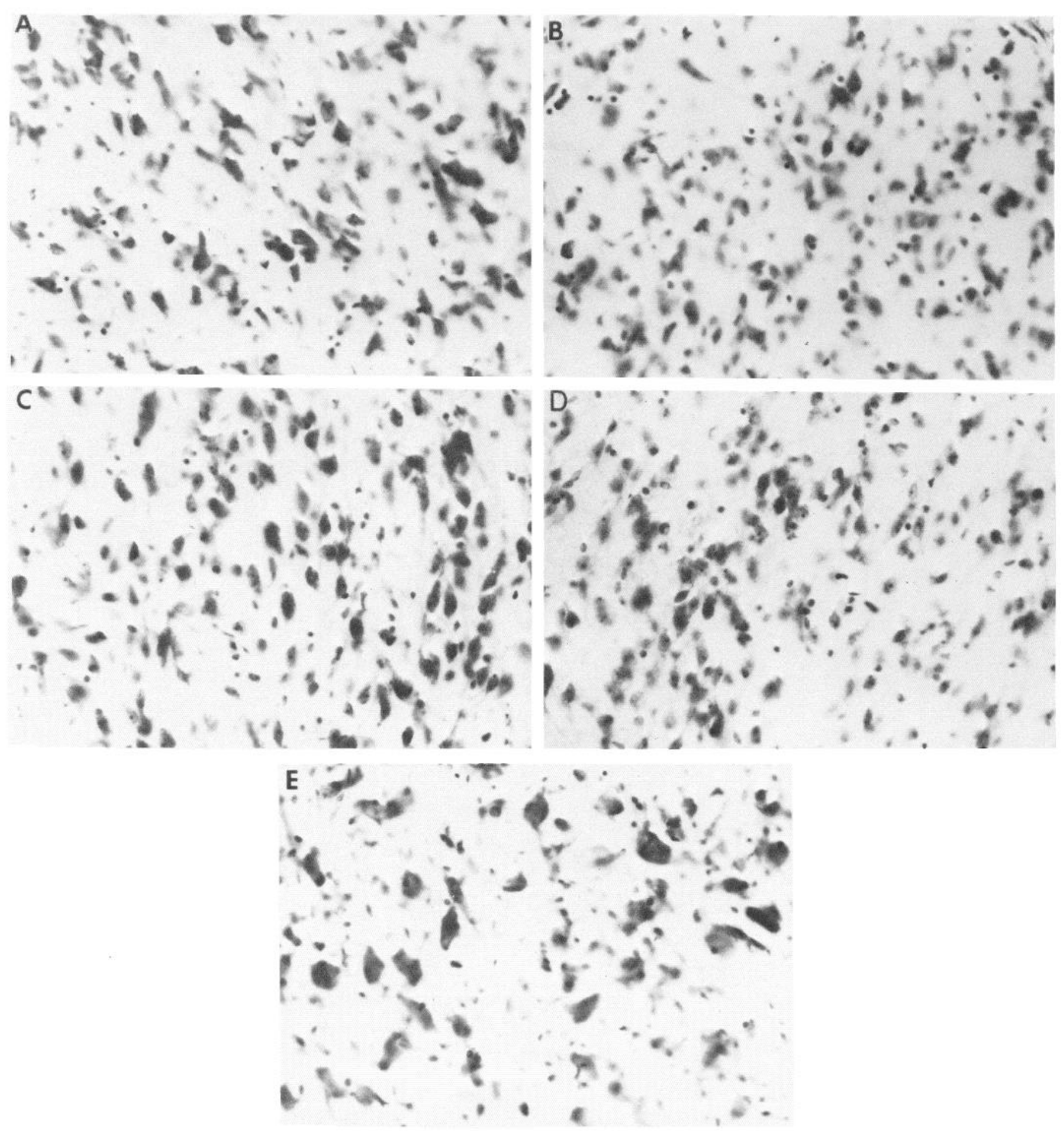

Figure 3. Photomicrographs of $60-\mu$ m-thick, thionin-stained sections from INAH-1 $(A)$, INAH-2 $(B)$, INAH-3 (C), INAH-4 $(D)$, and the SON (E).

incerta (Swanson et al., 1987). The MPN has been characterized immunohistochemically for the sexually dimorphic distribution of 5-HT fibers (Simerly et al., 1984), as well as for the presence of dopamine B-hydroxylase, neuropepeptide Y, cholecystokinin, substance $\mathrm{P}$, neurotensin, corticotropin-releasing factor, somatostatin, adrenocorticotropic hormone, alpha-melanocytestimulating hormone, leucine-enkephalin, and calcitonin generelated peptide immunoreactive fibers; and substance $P$, leucine- enkephalin, cholecystokinin, thyrotropin-releasing hormone, neurotensin, corticotropin-releasing factor, calcitonin gene-related peptide, and vasoactive intestinal polypeptide-containing cell bodies (Simerly et al., 1986). Sex differences in the medial preoptic area (MPOA) have been identified in receptors for opiates (Hammer, 1984), 5-HT (Fischette et al., 1983), and gonadal steroids in the rat (Rainbow et al., 1982; Jacobson et al., 1987) and gerbil (Commins and Yahr, 1985); for acetylcho- 


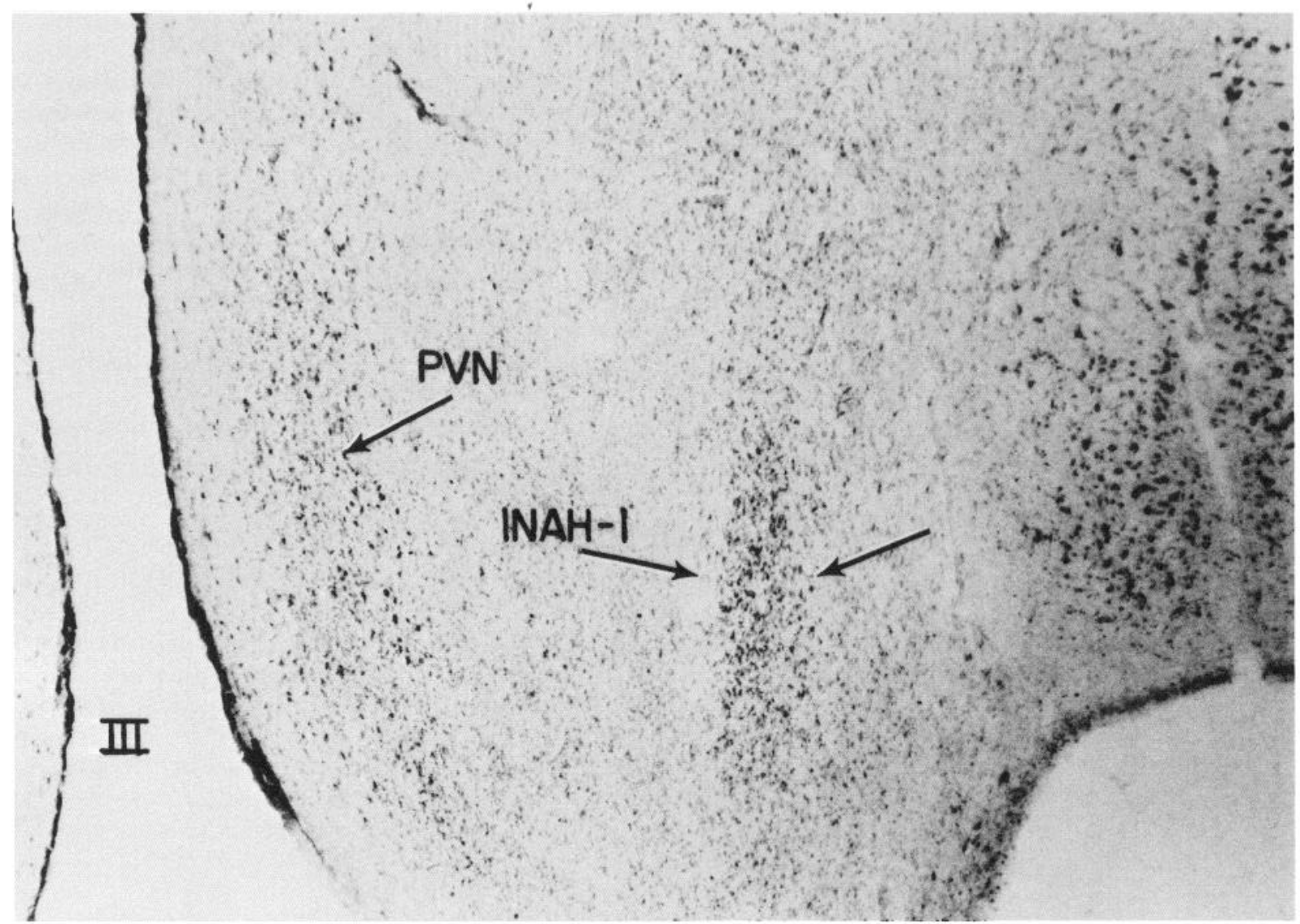

Figure 4. Photomicrograph $(60 \mu \mathrm{m})$ of INAH-1, from a 64-year-old female, which is in a slightly different plane of section than Figures 1 and 2 , appears to be the same nucleus that Swaab and Fliers (1985) named the "sexually dimorphic nucleus of the preoptic area" because of its shape, position in relation to adjacent structures, cell type, size relative to other nuclei in that region, and decrease in volume with advancing age (Table 1).

linesterase activity in the gerbil (Commins and Yahr, 1984); and for both acetylcholinesterase and choline acetyltransferase in the rat (Luine and McEwen, 1983).

Recently, considerable advances have been made in the localization of neurochemicals and receptors in the human brain, utilizing immunohistochemistry (Bouras et al., 1986), autoradiography (Palacios et al., 1986), and positron emission tomography (Stahl et al., 1986). Indeed, the link between sexual differentiation of the rat brain and that of the human brain will become clear with advancing time and technology. It is for this reason that we believe that the previously unnamed interstitial nuclei of the anterior hypothalamus (INAH) be described with this simple nomenclature and with a clear description of their anatomical locations (Figs. 1 and 2). Since there appears to be more than one sexually dimorphic nucleus in this region, and there is presently no indication that INAH-1 is homologous to the SDN-POA of the rat, we do not believe that it is appropriate for INAH-1 to be called the SDN-POA, regardless of its potential sexual dimorphism. Furthermore, INAH-1 extends into a region of the anterior hypothalamus that is not part of the POA (Figs. $1 ; 2, G, J$ ).

\section{Function}

Despite histological and histochemical characterization of sex differences in the MPN of the rodent, little is known about its function. Lesions of the MPOA in female rats (Powers and Valenstein, 1972) and lesions of the MPOA and particularly those including the SDN-POA (Hennessey et al., 1986) in male rats increase feminine sexual behavior. Although lesions of the POA decrease male reproductive behavior in both the rat (Arendash and Gorski, 1983) and primate (Slimp et al., 1978), specific lesions of the rat SDN-POA have not been shown to affect such behavior (Arendash and Gorski, 1983). However, SDN-POA volume positively correlates with both testosterone levels and masculine reproductive behavior in male rats (Anderson et al., 1986). Electrical stimulation of the monkey POA evokes penile erection, ejaculation, and mounting and thrusting behavior. Similarly, changes in neuronal activity in the POA of the male monkey have been related to sexual activity (Maclean and Ploog, 1962; Robinson and Mishkin, 1966; Oomura et al., 1983). Although the POA is essential for cyclic gonadotropin regulation in rodents (Gorski, 1968), it is apparently not necessary in primates; however, it probably plays a modulatory role (Plant et al., 1979; Pohl and Knobil, 1982).

\section{What determines sexual dimorphism?}

We do not know whether genomic determinants, environmental factors, and/or hormone levels influence the sex differences in INAH-2 and INAH-3. However, there is evidence that some facets of human behavior may be influenced by hormone levels during the perinatal period (Hines, 1982). In some species, structural neural sex differences are clearly affected by gonadal steroids. For example, in the rat (Gorski et al., 1978, 1980) and guinea pig (Hines et al., 1985), the steroid environment during 
perinatal development appears to determine the size of the sexually dimorphic nuclei. Indeed, gonadal hormones may serve as neurotrophic substances during the development of the $\mathrm{PO}$ AHA (Gorski, 1985). In other cases, such as the sexually dimorphic area of the gerbil and nuclei involved in song behavior in canaries, the prominence of the sexually dimorphic regions is affected by both the early hormonal environment and by adult hormone levels (Nottebohm, 1980, 1981; Commins and Yahr, 1984). In fact, steroid hormones may play a powerful role in neural plasticity in the adult brain by inducing dendritic growth and the formation of functional synapses (DeVoogd and Nottebohm, 1981; Matsumoto and Arai, 1981).

INAH-3 may resemble the SDN-POA of the rat and the guinea pig to the extent that its volume might be determined by early hormone exposure. It is consistently larger in males than in females, despite changing levels of steroid hormones throughout lifc. In contrast, INAH-2 may be similar to the sexually dimorphic cell groups of canaries and of gerbils in that its volume may change with fluctuations in circulating hormones. It is important to note, however, that our sample contained only 3 women of childbearing age and only 1 prepubescent pair. Clearly, further data are needed before any conclusions can be made regarding the possible influence of changing steroid titers on the volumes of INAH-2 and INAH-3.

\section{Asymmetry}

Although complete analysis of INAH $1-4$ and the SON were performed on only the right side of the brain, one investigator evaluated INAH $1-4$ on both sides of the brain, and observed no pattern of asymmetry. Although no asymmetries have been observed in the SDN-POA of the rat (Hines and Gorski, 1985), sex-related cerebral asymmetries have been reported in both the rat (Diamond et al., 1983) and the human (Wada ct al., 1975) which may be related to sex differences in estrogen receptor asymmetries in cortical regions (Sandhu et al., 1986).

\section{Is INAH-1 sexually dimorphic?}

During the course of the present study, Swaab and Fliers (1985) reported a sexually dimorphic nucleus in the human POA that resembles INAH-1 in location, size, shape, and cell type, and in its dramatic decrease in volume with advancing age. As shown in Figure 4, INAH-1 of a 64-year-old female brain, cut more obliquely than the other hypothalami, closely resembles-in terms of its location, relative orientation, and shape-the published photograph of what Swaab and Fliers named the "SDNPOA." In our serial-section study of the PO-AHA, no other nuclei besides INAH-1 resembled the nucleus described by Swaab and Fliers in terms of volume; INAH-1 was the largest distinct cell group besides the SON and PVN, and was several-fold larger than INAH-2-4. The fact that Swaab and Fliers reported the nucleus they studied to be $61 \%$ smaller than INAH- 1 is probably due to different methods of histological preparation. INAH-1 was evaluated in gelatin-embedded $60 \mu \mathrm{m}$ sections, while Swaab and Fliers evaluated their tissue in paraffin-embedded $6 \mu \mathrm{m}$ sections. Moreover, the borders of the rat SDN-POA at $6 \mu \mathrm{m}$ are difficult to define and the volume appears to be approximately $60 \%$ smaller than that calculated from the $60 \mu \mathrm{m}$ sections we use routinely for SDN-POA volume quantification (Gorski et al., 1980).

Although we firmly believe that the nucleus studied by Swaab and Fliers is the same as INAII-1, we can only speculate as to why they determined this nucleus to be 2.5 times larger in the male brain, whereas we found that INAH-1 was only 1.2 -fold larger in males than in females, prior to brain weight adjustment. Most likely, some discrepancy is due to the fact that our subjects were age-matched, with the average age of females being 2 months less than the average age of males. In contrast, in the Swaab and Fliers study, females were an average of over 10 years older than the males. Since INAH- 1 decreases with age, this age difference may have contributed to the significant differences between their male and female groups. The 2 methods of volumetric quantification were also markedly different. While we had 3 independent investigators quantify serial $60-\mu$ m-thick sections with an average of 29.5 sections per individual INAH-1, Swaab and Fliers quantified the areas of every 25 th $6-\mu \mathrm{m}$-thick section, except at the rostral and caudal ends of the nucleus, where every 5 th section was measured, for an average of 11 sections actually evaluated. In addition, different population samples may have contributed to different results. In studies of the rat, for example, different results are sometimes obtained in different strains of animals and with different rearing conditions. Although it is not possible to match all variables in human research as well as it is in animal research, we have included information as to race as it appeared on the autopsy report (Table 1) since this factor can influence the results.

Alternatively, it is possible that, although the volume of INAH-1 is not sexually dimorphic in $60 \mu \mathrm{m}$ sections, there is a sexually dimorphic subcomponent of INAH-1 that, because of greater cell density, may have been the only component of INAH- 1 visible in the $6 \mu \mathrm{m}$ sections examined in the Swaab and Fliers study. However, in the rat, although there are sexually dimorphic subcomponents to the SDN-POA, the volume of this nuclcus is approximatcly the same fold larger in males than in females, irrespective of whether 60 or $6 \mu \mathrm{m}$ sections are analyzed. We plan to examine cell density in a further study of the INAH.

\section{Conclusion}

Because the human being cannot be manipulated experimentally as can laboratory animals, it is difficult to extrapolate from animals to humans regarding structural, behavioral, or physiological sex differences. It is interesting to speculate that factors such as prenatal stress that both feminize and demasculinize sexual behavior (Ward, 1984) and decrease the volume of the SDN-POA in male rats (Anderson et al., 1986) may, similarly, contribute in human males to homosexuality (Dörner, 1976) and to a decrease in the volume of the sexually dimorphic INAH; moreover, the INAH are located in a region of the brain influencing sex differences in gonadotropin secretion which may be altered in some homosexual men (Dörner, 1976; Gladue et al., 1984). Furthermore, gonadal hormones may be important neurotrophic factors in both the developing and adult human and, in fact, have been shown to improve symptoms of Alzheimer's disease in some postmenopausal women (Fillit et al., 1986). Thus, morphological analysis of the brains from humans with different sexual orientations and identities, during different stages of development, and from individuals exposed perinatally to atypical steroid hormones or therapeutically to altered adult hormone levels may lead to further deductions concerning the possible influence of sex hormones on the structure and function of the human brain. 


\section{References}

Allen, L. S., and R. A. Gorski (1986) Sexual dimorphism of the human anterior commissure. Anat. Rec. 214:3A.

Allen, L. S., and R. A. Gorski (1987) Sex differences in the human massa intermedia. Soc. Neurosci. Abstr. 13: 46.

Anderson, R. H., D. E. Fleming, R. W. Rhees, and E. Kinghorn (1986) Relationships between sexual activity, plasma testosterone, and the volume of the sexually dimorphic nucleus of the preoptic area in prenatally stressed and non-stressed rats. Brain Res. 370: 1-10.

Arendash, G. W., and R. A. Gorski (1983) Effects of discrete lesions of the sexually dimorphic nucleus of the preoptic area or other medial preoptic regions on the sexual behavior of male rats. Brain Res. Bull. 10: 147-154.

Ayoub, D. M., W. T. Greenough, and J. M. Juraska (1983) Sex differences in dendritic structure in the preoptic area of the juvenile macaque monkey brain. Science 219: 197-198.

Bouras, C., P. J. Magistretti, and J. H. Morrison (1986) An immunohistochemical study of six biologically active peptides in the human brain. Human Neurobiol. 5: 213-226.

Burington, R. S. (1965) In Handbook of Mathematical Tables and Formulas, pp. 17, McGraw-Hill, New York.

Commins, D., and P. Yahr (1982) Adult testosterone levels influence the morphology of a sexually dimorphic area in the Mongolian gerbil brain. J. Comp. Neurol. 224: 132-140.

Commins, D., and P. Yahr (1984) Acetylcholinesterase activity in the sexually dimorphic area of the gerbil brain: Sex differences and influences of adult gonadal steroids. J. Comp. Neurol. 224: 123-131.

Commins, D., and P. Yahr (1985) Autoradiographic localization of estrogen and androgen receptors in the sexually dimorphic area and other regions of the gerbil brain. J. Comp. Neurol. 231: 473-489.

del Abril, A., S. Segovia, and A. Guillamon (1987) The bed nucleus of the stria terminalis in the rat: Regional sex differences controlled by gonadal steroids early after birth. Dev. Brain Res. 32: 295-300.

de LaCoste-Utamsing, C., and R. L. Holloway (1982) Sexual dimorphism in the human corpus callosum. Science 216: 1431-1432.

DeVoogd, T., and F. Nottebohm (1981) Gonadal hormones induce dendritic growth in the adult avian brain. Science 214: 202-204.

Diamond, M. C., R. E. Johnson, D. Young, and S. S. Singh (1983) Age-related morphologic differences in the rat cerebral cortex and hippocampus: Male-female; right-left. Exp. Neurol. 81: 1-13.

Dörner, G. (1976) Hormones and Brain Differentiation, Elsevier/NorthHolland Biomedical, Amslerdam.

Dörner, G., and J. Staudt (1968) Structural changes in the preoptic anterior hypothalamic area of the male rat, following neonatal castration and androgen substitution. Neuroendocrinology 3: 136-140.

Fahrbach, S. E., J. I. Morrell, and D. W. Pfaff (1986) Identification of medial preoptic neurons that concentrate estradiol and project to the midbrain in the rat. J. Comp. Neurol. 247: 364-382.

Fillit, H., H. Weinreb, I. Cholst, V. Luine, R. Amador, J. B. Zabriskie, and B. S. McEwen (1986) Hormonal therapy for Altheimer's disease. In Treatment Development Strategies for Alzheimer's Disease, T. Crook, R. Bartus, S. Ferris, and S. Gershon, eds., pp. 311-336, Mark Powley, Madison, CT.

Fischette, C. T., A. Biegon, and B. S. McEwen (1983) Sex differences in serotonin 1 receptor binding in the rat brain. Science 222: 333335.

Gladue, B. A., R. Green, and R. E. Hellman (1984) Neuroendocrine response to estrogen and sexual orientation. Science 225: 1496-1498.

Gorski, R. A. (1968) The neural control of ovulation. In Biology of Gestation, Vol. 1: The Maternal Organism, N. S. Assali, ed., pp. 166, Academic, New York.

Gorski, R. A. (1974) The neuroendocrine regulation of sexual behavior. Adv. Psychobiol. 2: 1-58.

Gorski, R. A. (1984) Critical role for the medial preoptic area in the sexual differentiation of the brain. Prog. Brain Res. 61: 129-146.

Gorski, R. A. (1985) Gonadal hormones as putative neurotrophic substances. In Synaptic Plasticity, C. W. Cotman, ed., pp. 287-310, Guilford, New York.

Gorski, R. A., J. H. Gordon, J. E. Shryne, and A. M. Southam (1978) Evidence for a morphological sex difference within the medial preoptic area of the rat brain. Brain Res. 148: 333-346.

Gorski, R. A., R. E. Harlan, C. D. Jacobson, J. E. Shryne, and A. M. Southam (1980) Evidence for a morphological sex difference within the medial preoptic area of the rat brain. J. Comp. Neurol. 193: 529539.

Goy, R. W., and B. S. McEwen (1980) In Sexual Differentiation of the Brain, MIT Press, Cambridge, MA.

Greenough, W. T., C. S. Carter, C. Steerman, and T. J. DeVoogd (1977) Sex differences in dendritic branching patterns in hamster preoptic area. Brain Res. 126: 63-72.

Hammer, R. P. (1984) The sexually dimorphic region of the preoptic area in rats contains denser opiate receptor binding sites in females. Brain Res. 308: 172-176.

Hennessey, A. C., K. Wallen, and D. A. Edwards (1986) Preoptic lesions increase the display of lordosis by male rats. Brain Res. 370: 21-28.

Hines, M. (1982) Prenatal gonadal hormones and sex differences in human behavior. Psychol. Bull. 92: 56-80.

Hines, M., and R. A. Gorski (1985) Hormonal influences on the development of neural asymmetries. In The Dual Brain, D. F. Benson and E. Zaidel, eds., pp. 75-96, Guilford, New York.

Hines, M., F. C. Davis, A. Coquelin, R. W. Goy, and R. A. Gorski (1985) Sexually dimorphic regions in the medial preoptic area and the bed nucleus of the stria terminalis of the guinea pig brain: A description and an investigation of their relationship to gonadal steroids in adulthood. J. Neurosci. 5: 40-47.

Jacobson, C. D., J. Terkel, R. A. Gorski, and C. H. Sawyer (1980) Effects of small medial preoptic area lesions on maternal behavior: Retricving and nest building in the rat. Brain Res. 194: 471-478.

Jacobson, C. D., A. P. Arnold, and R. A. Gorski (1987) Steroid autoradiography of the sexually dimorphic nucleus of the preoptic area. Brain Res. 414: 349-359.

Luine, V. N., and B. S. McEwen (1983) Sex differences in cholinergic enzymes of diagonal band nuclei in the rat preoptic area. Neuroendocrinology $36: 475-482$.

Maclean, P. D., and D. W. Ploog (1962) Cerebral representation of penile erection. J. Neurophysiol. $25: 29-55$.

Matsumoto, A., and Y. Arai (1981) Effect of androgen on sexual differentiation of synaptic organization in the hypothalamic arcuate nucleus: An ontogenetic study. Neuroendocrinology 33: 166-169.

Meyers, P. E., and J. H. Gordon (1982) Sexually dimorphic dendritic organization in the preoptic area of the neonatal rat. Soc. Neurosci. Abstr. 8: 637.

Nishizuka, M., and Y. Arai (1981) Sexual dimorphism in synaptic organization in the amygdala and its dependence on neonatal hormone environment. Brain Res. 212: 31-38.

Nottebohm, F. (1980) Testosterone triggers growth of brain vocal control nuclei in adult female canaries. Brain Res. 189: 429-436.

Nottebohm, F. (1981) A brain for all seasons: Cyclical anatomical changes in song control nuclei of the canary brain. Science $214: 1368$ 1370 .

Nottebohm, R., and A. P. Arnold (1976) Sexual dimorphism in vocal control areas of the songbird brain. Science 194: 211-213.

Oomura, Y., H. Yoshimatsu, and S. Aou (1983) Medial preoptic and hypothalamic neuronal activity during sexual behavior of the male monkey. Brain Res. 266: 340-343.

Palacios, J. M., A. Probst, and R. Cortcs (1986) Mapping reccptors in the human brain. Trends Neurosci. 9: 284-289.

Panzica, G. C., C. Viglietti-Panzica, M. Calacagni, G. C. Anselmetti, M. Schumacher, and J. Balthazart (1987) Sexual differentiation and hormonal control of the sexually dimorphic medial preoptic nucleus in the quail. Brain Res. 416: 59-68.

Pfaff, D. W. (1966) Morphological changes in the brains of adult male rats after neonatal castration. J. Endocrinol. 36: 415-416.

Plant, T. M., J. Moossy, D. L. Hess, Y. Nakai, J. T. McCormack, and E. Knobil (1979) Further studies on the effects of lesions in the rostral hypothalamus on gonadotropin secretion in the female rhesus monkey (Macaca mulatta). Endocrinology 105: 465-473.

Pohl, C. R., and E. Knobil (1982) The role of the central nervous system in the control of ovarian function in higher primates. Annu. Rev. Physiol. 44: 583-593.

Powers, B., and E. S. Valenstein (1972) Sexual receptivity: Facilitation by medial preoptic lesions in female rats. Science $175:$ 1003-1005.

Rabl, R. (1958) Strukturstudien an der massa intermedia des thalamus opticus. J. Hirnforschung 4: 78-112.

Rainbow, T. C., B. Parsons, and B. S. McEwen (1982) Sex differences in rat brain oestrogen and progestin receptors. Nature 300: 648-649. 
Raisman, G., and P. M. Field (1971) Sexual dimorphism in the preoptic area of the rat. Science 173: 731-733.

Robinson, B. W., and M. Mishkin (1966) Ejaculation evoked by stimulation of the preoptic area in monkeys. Physiol. Behav. 1: 269-272.

Sandhu, S., P. Cook, and M. C. Diamond (1986) Rat cerebral cortical estrogen receptors: Male-female, right-left. 92: 186-196.

Simerly, R. B., and L. W. Swanson (1986) The organization of neural inputs to the medial preoptic neucleus of the rat. J. Comp. Neurol. 246: 312-342.

Simerly, R. B., L. W. Swanson, and R. A. Gorski (1984) Demonstration of a sexual dimorphism in the distribution of serotonin immunoreactive fibers in the medial preoptic nucleus of the rat. J. Comp. Neurol. 225: 151-166.

Simerly, R. B., R. A. Gorski, and L. W. Swanson (1986) Neurotransmitter specificity of cells and fibers in the medial preoptic nucleus: An immunohistochemical study in the rat. J. Comp. Neurol. 246: 343-363.

Slimp, J. C., B. L. Hart, and R. W. Goy (1978) Heterosexual, autosexual and social behavior of adult male rhesus monkeys with medial preoptic anterior hypothalamic lesions. Brain Res. 142: 105-122.

Stahl, S. M., K. L. Leenders, and N. G. Bowery (1986) Imaging neu- rotransmitters and their receptors in living human brain by positron emission tomography. Trends Neurosci. 9: 241-245.

Swaab, D. F., and E. Fliers (1985) A sexually dimorphic nucleus in the human brain. Science 228: 1112-1114.

Swanson, L. W., G. J. Mogenson, R. B. Simerly, and M. Wu (1987) Anatomical and electrophysiological evidence for a projection from the medial preoptic area to the mesencephalic and subthalamic locomotor regions' in the rat. Brain Res. 405: 108-122.

Tobet, S. A., D. J. Zahniser, and M. J. Baum (1986) Sexual dimorphism in the preoptic/anterior hypothalamic area of ferrets: Effects of adult exposure to sex steroids. Brain Res. 364: 249-257.

Wada, J. A., R. Clarke, and A. Ilamm (1975) Cerebral hemispheric asymmetry in humans. Arch. Neurol. 32: 239-246.

Ward, I. L. (1984) The prenatal stress syndrome: Current status. Psychoneuroendocrinology 9: 3-11.

Wiegand, S., and E. Terasawa (1982) Discrete lesions reveal functional heterogeneity of suprachiasmatic structures in regulation of gonadotropin secretion in the female rat. Neuroendocrinology 34: 395-404.

Yahr, P., and D. Commins (1982) The neuroendocrinology of scent marking. In Chemical Signals in Vertebrates, Vol. 2, R. M. Silverstein and D. Muller-Schwarze, eds., pp. 119-133, Plenum, New York. 